\title{
Research and Emphasis on Young Women's Demand for Sports Bra
}

\author{
Puyu $\mathrm{Wu}^{1} \&$ Yanmei $\mathrm{Li}^{1}$ \\ ${ }^{1}$ College of fashion, Shanghai University of Engineering Science, Shanghai, China \\ Correspondence: Yanmei Li, Costume Institute, Shanghai University of Engineering Science, Shanghai, China.
}

Received: October 25, 2017

Accepted: November 16, 2017

Online Published: January 9, 2018

doi:10.5430/jbar.v7n1p1

URL: https://doi.org/10.5430/jbar.v7n1p1

\begin{abstract}
The era is always in progress, people on the pursuit of health and quality of life are more intense, sports bra as a newer sportswear category, is still in the development stage. In the current market, large differences in products' price, propaganda is not enough, comfortableness also need to be strengthened. In view of these problems, this article mainly through the literature to understand the current situation of domestic and international sports bra research, while the domestic sports bra market research, and through the form of questionnaire to grasp the young women's understanding and demand for sports bra, Consumers are mostly low-frequency movement, and hope that the future in the sports bra study, for this movement to design a more appropriate sports bra to better meet the consumer.
\end{abstract}

Keywords: Clothing pressure, Sports bra, Young women

In recent years, more and more people enjoy exercise and pay attention to sports costume especially in sports bra. Related studies have shown that half women felt breast pain in the movement. Elastic fiber tissue inside the chest may be injured, extremely the chest sagging and deformation. Sports bras, which are specially worn in sports, should play a key role in protecting the breast and reducing the movement of women's breasts. According to the survey, many women prepare a few sports bras for exercise. There are still some women don't understand sports bra, but we can find sports bra is a huge potential market. Sports bras' audience is young women, so investigation and research this group to understand the demand and cognitive situation of the sports bras. And then hope to suggest for relevant enterprises or companies.

\section{Research Design}

\subsection{Research Background}

Sports bra based on the bra, basically is the structure and characteristics of bra, unlike ordinary bra, it is a specialized underwear dress when women in the movement, is characterized by short, stick put oneself, good elasticity, main function is to protect the body movement when breast, have the effect of retainer, mobile support, restrictions on breast, avoid breast muscle, tissue damage, does not prevent movement, has the protection function, shockproof, moisture absorption, perspiration ${ }^{[1]}$.Sports bra through the use of model design and functional materials, achieving good support and bound effect, make the movement of the breasts and body together, thus improving campaigners motion state, improve the efficiency of movement.

Through the study of foreign literature data, some major conclusions are drawn: 1) Full-cup sports bras have greater pressure under the chest, and the pressure of $3 / 4$ cup is more balanced.2) The maximum static pressure parts of sports bra is the shoulder, side and back, and the dynamic pressure is greater than the static pressure;3)The comfort of sports bra is related to the clothing pressure, and the dynamic influencing factor is one of the important parameters of the bra design.4) The vertical displacement of the breast is significantly greater than that of other directions, when women in motion.

Through domestic literature research, some main conclusions are drawn: 1) The sports corset with double elastic fabric has the most protective effect in motion.2) The pressure is too small, not conducive to the improvement of body protection and movement efficiency; the pressure is too big, easy to damage the health ;3) A three-dimensional human model can be used to study the pressure of the breasts on the corset. At present, traditional brands like Nike and Adidas product sports bra for consumers, but the style is not much, can supply consumers choice less, and the price is between $400-600$ commonly. 


\subsection{Investigation Objects}

Because the market for sports bras is still in development phase, there is a lot of research value in women who know or don't understand sports bras. Young women mean the ages of 18 and 44 . Therefore, the questionnaires filled out by women aged over 44 were treated as invalid questionnaires.

\subsection{Purpose of Investigation}

To realize the consumption demand and market situation of women's youth for sports bras, and grasp the comfort of the existing sports bra.

\subsection{Questionnaire Design and Recall}

According to the relevant literatures, the questionnaire was designed as follows. The first part: the basic situation (age, education, monthly consumption) and personal sports situation (sports frequency); the second part: consumption behavior (purchase motivation, purchase price, purchase route, purchase focus); Part 3: suggestions for sports bra design (wear problems, preference choices).

The questionnaires were distributed online and offline, there were 197 online questionnaires and 26 offline questionnaires. So, there were 227 questionnaires, 212 valid questionnaires and the efficiency is $93.4 \%$.

\subsection{Investigation Method}

Analyzed the results of questionnaires by SPSS17.0 statistical software. The aim is to summarize and summarize the needs of young women for sports bras, so that enterprise can make more satisfying products for customers.

\section{Investigation Results and Analysis}

In general, the prospect of sports bra market is wide. Both at home and abroad have made some breakthrough in this field, but overall, the research and development of sports bra is still in the primary level. And the sports bra that sell on the market cannot satisfy the requirement of customers.

\subsection{Sample Analysis}

\subsubsection{Sample Basic Situation Analysis}

Most of the survey was between the ages of 18 and 25, it means that the results more reflected the demand for sports bras for youngish women. Considered the most respondents are mostly students who have less income, so the cost can be used to judge consumption ability. The survey showed that $89.85 \%$ of women spent less than 4,000 yuan per month. The data also showed that only $12.08 \%$ of women did not participate in sports, meaning that most women were in low-frequency, low-intensity exercise.

In general, in this survey are characterized by a low age, low consumption and low frequency movement.

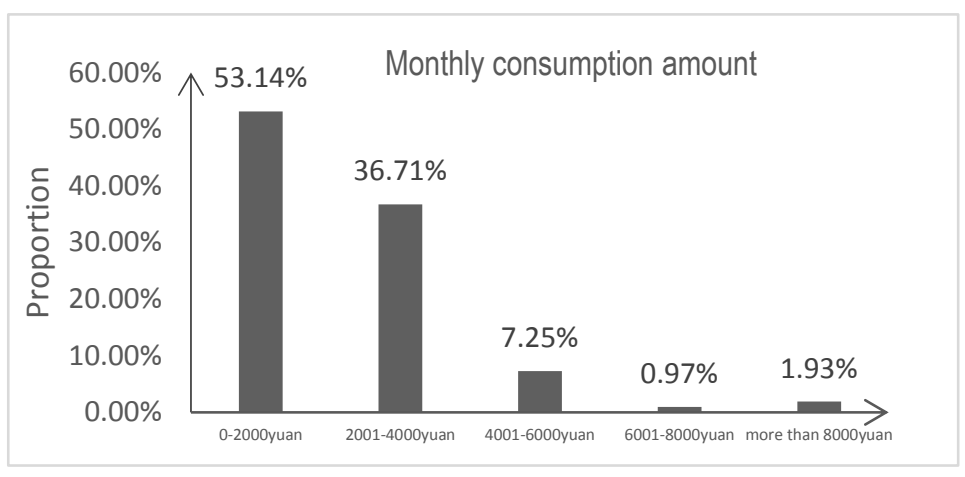

Figure 1. Monthly Consumption

\subsubsection{Cross-analysis of Samples}

Fig. 2 and Fig. 3 are the results of the cross-analysis. Fig 2 shows the age and educational background as the independent variables, and the purchase way of sports bra is the dependent variable. Fig 3 shows the monthly consumption as the independent variable, and the purchase route of sports bra as the dependent variable. By the Further analysis, it shows that the women who are 18-25 years old with a bachelor's degree are more likely to buy sports bra online. 


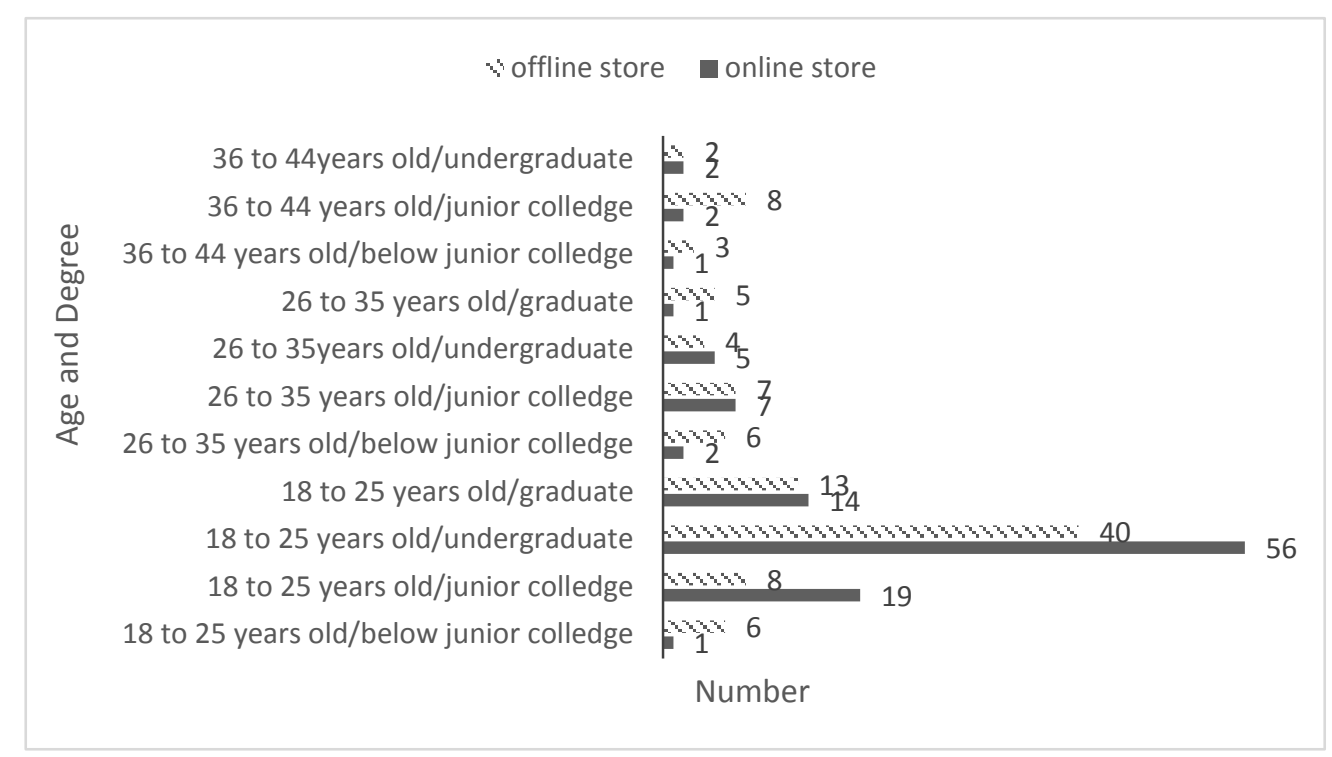

Figure 2. different age and education analysis with purchase way

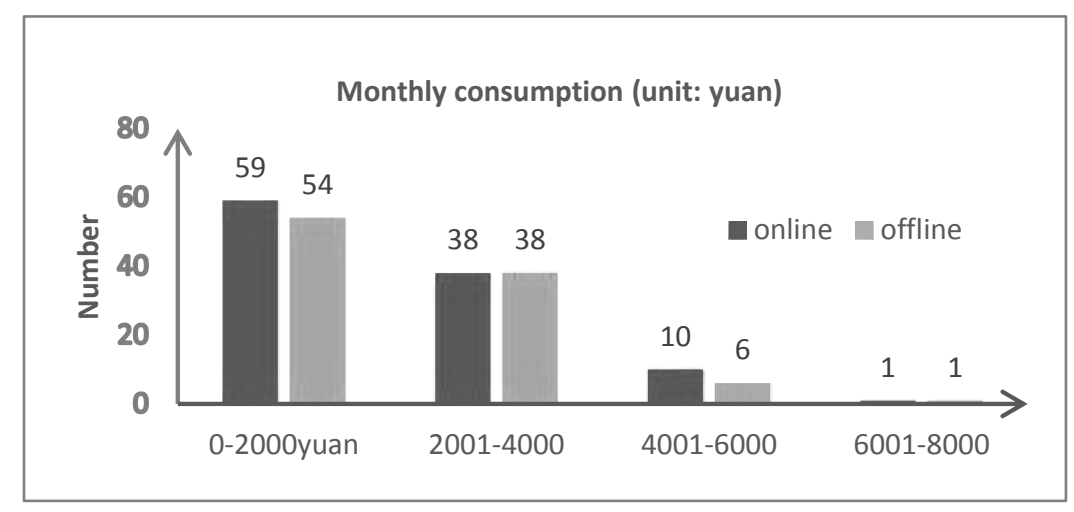

Figure 3. consumption analysis with purchase way

At the same time, the survey reflects that reasons of buying online are low price, timesaving, convenient, complete category and so on. It is worth mentioning that low prices are the most popular reason for online shopping, and it is not difficult to explain why customers who choose to buy online are more concentrated in the lower monthly consumption. Online sales of sports bras are mostly unbranded clothing, which has a great price advantage due to its short supply and distribution chain. Moreover, high efficiency and fast network can not only make full display of the clothing, but also can break the regional restrictions and weaken the phenomenon less sports underwear brand in domestic, you can choose their own through a network of domestic and foreign brand clothing. Consumers can choose your favorite domestic and foreign brand clothing through the Internet. In addition, the interactivity and entertainment of the Internet has attracted a number of female consumers who are willing to buy sports bras online as a way of recreation. From previous analysis, it can be found that younger people aged 18 to 25 are more likely to buy online, so their novelty mentality is also an important reason why they choose the network shopping.

\subsection{Research on Sports Bra Recognition}

Because sports bra in China started late, it is not very high on the popularity of consumer. Then, the questionnaire is also made on the investigation of the reasons for this phenomenon. By asking respondents whether they want to wear sports bras when exercise, it is concluded that $67.63 \%$ of women would wear sports bras, $32.37 \%$ of women said don't want to wear sports bras, and there are more than $80 \%$ of women to write the reason is not understand the sport bra, and a small number of people said it is not necessary to wear sports bra. Double tail correlation by using SPSS software analysis test of concomitant probability is $0.191(>0.05)$, accept the hypothesis that two variables are not related, namely the degree that has nothing to do with sports bra recognition. It's found that the businessman media 
publicity of sports bra still needs to be improved, and also reflects the development of the sports bra is not enough mature in the domestic market, the product still has great room to improve.

\subsection{Investigation of Consumption Behavior}

As shown in figure 4, most women still care about the damage to their chest while exercising, hoping to protect their breasts by wearing a sports bra. But at the same time, young women have a lower rate of renewal of sports bras, far less than the popular dress. That means even sports bras have new style and promotions, it is also hard to stimulate consumers to buy it. Since the sports bra is aimed at young women and the particularity of the product, most women are rational in the face of the purchase of sports bras, and seldom have impulse consumption. Therefore, businesses should focus more on products. The data suggest that more than 90 percent of women are accept price of sports bra under 300 yuan. Through cross double factor analysis, monthly consumption as independent variables, accept sports bra price as the dependent variable. It can be found that as the monthly consumption increases, the price acceptance of sports bras also increases.

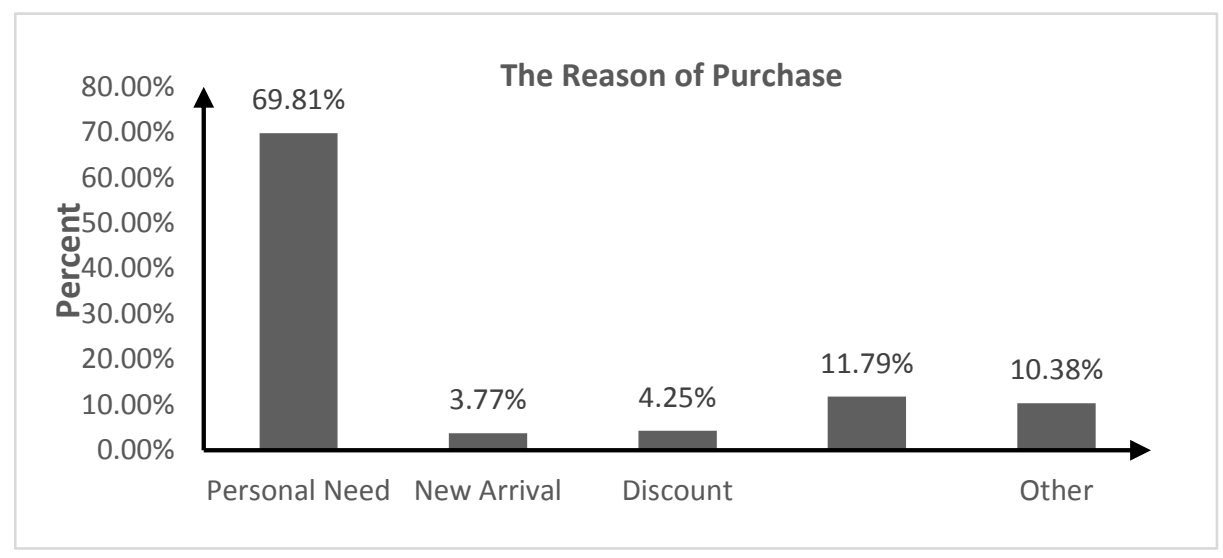

Figure 4. the reason of buying sports bras

It's found the proportion of online shopping is similar to proportion of entity shop through analyze the purchase way. With the rapid development of Internet shopping, because of sports bra's privacy and fit, there are still many women willing to buy it offline. They believe that physical stores are more intuitive to choose suitable sports bras. Online purchases of sports bras are far less complex than those purchased in offline stores. Besides sports bra size was marked different, many women are not particularly aware of the size of their sports bra, and it is only appropriate for them to try on a real shop. The investigation also pointed out that young women have little demand for brands and colors in sports bras. They care more about the quality and comfort of clothing. So, firms need to focus more on how to improve the comfort and quality of sports bras. In this way it can better meet the needs of consumers.

\subsection{Suggestions for Sports Bras Design}

The study shows some common problems when they wear sports bra, such as, bra deformation, strap slipping, and skin trench. With so many problems, we found that sports bras do have a lot to improve. Maybe we can change the pressure of the straps and sports bra fabrics to reduce skin trench, and use more anti-wrinkle resistance fabrics to improve the deformation of sports bra.

Due to the body dimension update slower, shape standards are not detailed enough and the pattern drawing design unreasonable, underwear fabric develop slowly. In the meantime, sports bra design and color design cannot be ignored. With sports bra development, comfortable and fashion sports bra is more competitive.

Based on the analysis of the preferences, the following suggestions are made:

1) Select high - shot, wet - quality fabrics on the shoulder strap. And designing wide straps share the pressure to improve comfort. Then, we can control straps decline phenomenon with anti-slip design.

2) The cup part chooses soft absorbent and non-deformed fabrics, such as polyester and cotton blended fabric. Use full cup, thin design to reduce breast displacement in exercise.

3) The back adopts the I-shape design to reduce the cover area and movement resistance.

4) The design of the dividing line should not be designed in the cup, but it can be accepted in the front. 


\section{Summary}

1) Women between the ages of 18 and 44 are in low-frequency movement, companies can design more suitable sports bra based on their motion state.

2) The consumption behavior of young women is characterized by low purchase quantity, low frequency of elimination and high demand for product quality.

3) The most widely accepted price for sports bras is 101-300 yuan, and comfort, quality and style are the main products of purchase

4) The future market trend is sure to be networked, individualized and technology-based. The profound problem is consumers can buy suitable sports bra by more accurate foot code watch or technical means.

\section{References}

B. Ayres, J. White, W. Hedger, \& J. Scurr. (2013). Female upper body and breast skin temperature and thermal comfort following exercise. Ergonomics, 56(7), 1194-1202. https://doi.org/10.1080/00140139.2013.789554

De, S. J., Cheatham, C., \& Wittbrodt, M. (2014). The effects of a moisture-wicking fabric shirt on the physiological and perceptual responses during acute exercise in the heat. Applied Ergonomics, 45(6), 1447-53. https://doi.org/10.1016/j.apergo.2014.04.006

Mcghee, D. E., Power, B. M., \& Steele, J. R. (2007). Does deep water running reduce exercise-induced breast discomfort?. British Journal of Sports Medicine, 41(12), 879. https://doi.org/10.1136/bjsm.2007.036251

Morooka, H., Fukuda, R., Sasaki, H., \& Morooka, H. (2006). The effects of the tensile properties of cup-stand materials on clothing pressure and comfort of push-up type brassieres. Seni Gakkaishi, 62(12), 287-292. https://doi.org/10.2115/fiber.62.287

White, J. L., Scurr, J. C., \& Smith, N. A. (2009). The effect of breast support on kinetics during overground running performance. Ergonomics, 52(4), 492-498. https://doi.org/10.1080/00140130802707907

Wood, L. E., White, J., Milligan, A., Ayres, B., Hedger, W., \& Scurr, J. (2012). Predictors of three-dimensional breast kinematics during bare-breasted running. Medicine \& Science in Sports \& Exercise, 44(7), 1351. https://doi.org/10.1249/MSS.0b013e31824bd62c

Zhang, K. Z. K., \& Benyoucef, M. (2016). Consumer behavior in social commerce: a literature review. Decision Support Systems, 86(C), 95-108. https://doi.org/10.1016/j.dss.2016.04.001

Zhou, J., Yu, W., \& Ng, S. P. (2012). Studies of three-dimensional trajectories of breast movement for better bra design. Textile Research Journal, 82(3), 242-254. https://doi.org/10.1177/0040517511435004 